apart, and we shall then observe the time which an electromotive impulse communicated at one end takes to travel to the other. Instead of using two wires, we may if we like use what comes to much the same thing, viz. a single wire suspended at a reasonable height above the ground, as in a common land telegraph. Such a case as this is much the same as if two wires were used at a distance apart equal to about twice the height above the ground.

The experiment, if it could be accurately made, would result in the observation of a speed of propagation equal to $3 \times 10^{10}$ centimetres per second. The actual speed in practice may be less than this, by reason of the various circumstances mentioned, but it can never be greater. This, then, is the rate of transmission of transverse impulses, and therefore of transverse waves, through ether as free as it can be easily obtained.

There are many methods known to physicists by which an indirect experimental determination of this velocity can be made. These methods are more easily practicable than the one described: they directly determine the ratio $k / \mu$, or, what is the same thing, the product $\mathrm{K} \mu$, and it is left to theory to say that this is really the velocity of electrical pulses in free ether. It is unnecessary to say more about them here.

OLIVER J. LODGE.

(To be continued.)

\section{A HISTORY OF THE AUGUST METEORS.}

"THE August meteor-shower has been more frequently observed than any other with which we are acquainted, and the modern history of this remarkable system includes many interesting circumstances. It has not, in recent times, given us displays equal in grandeur to periodical swarms like the Leonids of November 13 and Andromedes of November 27, being decidedly less rich in point of numbers. But what this stream lacks in this respect is compensated for by the annual visibility of the shower and by the intense brilliancy of some of its individual members. Every year the August meteors present a conspicuous appearance on the night following St. Lawrence's Day, and fire-balls of excessive lustre are now and then interspersed with the smallest perceptible shooting-stars of the system. The Leonids and Andromedes, which have rendered the month of November so famous in meteoric annals, can only reappear abundantly at intervals of thirty-three and (probably) thirteen years, whereas the Perseids of August are unfailing in their regular apparitions as the epoch comes round each year. On the night of the Ioth the most casual observer will not fail to notice the surprising frequency of shooting-stars, and must remark their occasional brilliancy and the persistency of the phosphorescent after-glows which they generate during their rapid tilights amongst the fixed stars.

The early history of the August meteors is vague and meagre in the extreme. Ancient writings are significantly mute as to the scientific aspect of meteor-showers. Doubtless in olden times these phenomena were equally as plentiful as at present, but amid the ignorance and superstition which prevailed they were little regarded. The prominent part which meteors play in the solar system was not suspected, hence no importance was attached to their appearance. They were supposed to be mere exhalations uncontrolled by fixed laws, and it is entirely due to modern science that their true character has been revealed, and that they have been raised to the dignity of bodies having a celestial origin, and probably also an extensive influence throughout the wide range of astronomical physics.

But former records, if void of particulars possessing a scientific utility, are yet often useful in supplying dates. Many old references to meteor-showers, though very imperfect in description, are, by the accordance of epoch, justly assumed to have been early exhibitions of the very same systems as those which have furnished some of the most imposing displays of recent years. In the catalogue of 315 meteoric showers compiled by Quetelet, a considerable proportion are probably identical with the August Perseids, and below we give the dates, up to a century ago, of these :-

$\begin{array}{lll}\text { Year. } & & \text { Date. } \\ 8 \text { I I } & \text { July } & 25 \\ 820 & , & 25-30 \\ 824 & , & 26-28 \\ 830 & \Rightarrow & 26 \\ 833 & , & 27 \\ 835 & , & 26 \\ 841 & , & 25-30 \\ 924 & , & 27-30 \\ 925 & , & 27-30\end{array}$

\begin{tabular}{rcc} 
Year. & \multicolumn{2}{c}{ Date. } \\
926 & July & $27-30$ \\
933 & $\#$, & $25-30$ \\
1243 & Aug. & 2 \\
1451 & $\#$ & 7 \\
1709 &, & 8 \\
1779 &, & 9 and 10 \\
1781 &, & 8 \\
1784 &, & 6 \\
1789 &, & 10
\end{tabular}

The dates in the ninth and tenth centuries are somewhat different from those in later years, but this does not negative the assumed relation, because they are brought nearly into agreement when the change of style in $175^{2}$ is allowed for. This proves the showers to have really occurred at a period early in August according to present reckoning. There may also be a slight alteration in the epoch of the swarm due to a shifting of the node, which, in its cumulative amount after many ages, might reach a considerable value. For the reasons assigned, the celebrated shower of Leonids which now takes place on November 13 was observed in October 902, and again on October 19, 1 202, October 22, 1 366, \&c.

Muschenbroek, in 1762 , announced the general fact that he had observed shooting-stars to be more plentiful in August than in any other month of the year. Further towards the close of the century this was in part confirmed by the apparition of many meteor's on August 8 and 9 . In 1806 and 1812 , Dr. Forster, of Clapton, recorded in his "Calendar" that these phenomena were unusually abundant on August 10, and in the latter year he particularly noted the extraordinary length and phosphorescent aspect of the trains left in their wake. Subsequently the same epoch was amply corroborated; and in 1835 . Quetelet definitely mentioned the 9 th and roth of August as the date of maximum annual display.

On August 9, r837, M. Wartman, of Geneva, observed $S_{2}$ of these meteors between 9 p.m. and midnight. In the following year, on August Io, observations were made at Geneva and at Planchettes, a village 62 miles north-east of Geneva, with the view of determining the heights and velocities of the meteors. A discussion of the results showed that the average elevation above the ground was 550 miles, and the velocity 220 miles, but these figures are now known to have been enormously in excess of the true values.

From 20 meteors observed in August 1863, Prof. A. S. Herschel determined the mean height as $8 \mathrm{I}^{\circ} 6$ miles at first appearance and 57.7 miles at disappearance, and the velocity was found to be $34^{\circ} 4$ miles per second. From 27 meteors similarly observed in Italy between August 5 and Io, 1864, Secchi derived limiting heights of 76.6 and 497 miles; and, averaging these with the results obtained by Prof. Herschel in the preceding year, we get 78 to 54 miles, which may be adopted as representative values for the normal heights not only of the Perseids, but of shooting-stars generally.

Heis, Schmidt, Greg, and Herschel were amongst the first to methodically observe the August meteor-shower and determine its radiant point in the northern region of Perseus. In 1863, August 10, an unusual display was witnessed, for on this occasion the stream seems to have attained a degree of intensity not recorded either before or subsequently to that year. In $187 \mathrm{I}$ there was also a very pronounced and abundant appearance of these meteors. In NATURE, vol. xx. p. 457 (September 11, 1879), will be found some details as to the relative number of August meteors counted in different years. 
But the epoch of 1866 is perhaps the most eventful and interesting of all in the history of this notable group. Signor Schiaparelli, of Milan, in the course of some observations of the Perseids, was led to take up the investigation of the theory of shooting-stars. Cautiously sifting the available materials, and forming deductions from facts indicated by the best authorities on the subject, he was induced to the belief that meteors were small particles composing cosmical clouds. These clouds were, by the action of gravitation, spread out into streams, and their orbits formed, like those of comets, elongated conic sections. From a method explained by Prof. Erman, he computed the orbital elements of the August meteors and of certain other streams, and, comparing them with the orbits of comets, discovered two remarkable coincidences between the system of Perseids and Comet III. I 862, and the Leonids and Comet I. I865. In each case the paths of the meteor group and comet were identical, and every circumstance favoured the inference that the two phenomena were physically identical, the meteors forming the dispersed material of the comet. The period of the Leonids (November I3), viz. $33 \frac{1}{4}$ years, agreed precisely with that of their supposed parent comet. The period of the August display, however, remained doubtful, the ellipse being more elongated; but Schiaparelli adopted a cycle of rather more than Ioo years, as best satisfying the observations, though the exact period is still doubtful.

Computation showed that the radiant point of meteoric particles following the track of Comet III. I 862 would be seen, on August ro, at R.A. $43^{\circ}$, Decl. $57 \frac{1}{2}^{\circ} \mathrm{N}$. In 1863, on August 10, Prof. Herschel had observed the meteors, and fixed their radiant at R.A. $44^{\circ}$, Decl. $56^{\circ} \mathrm{N}$., a wonderfully close agreement, considering the difficulties attached to such observations. This, and other coincidences of orbit, removed all doubts as to the affinity of meteors and comets; and later evidence, especially that afforded by Biela's comet and the splendid meteorshowers of November 27, I 872 and I 885 , has afforded convincing proofs as to the validity of the theory enunciated by the Italian astronomer.

Some interesting features in connection with the August meteors still, however, awaited further investigation. The visible duration of the shower was unknown. The radiant was thought to be diffused over a region extending from Perseus to Cassiopceia. Mr. R. P. Greg, in his "Table of Radiants" (Monthly Notices, I872, p. 353), places it over the area from R.A. $50^{\circ}-25^{\circ}$, Decl. $44^{\circ}$ N., to R.A. $50^{\circ}-65^{\circ}$, Decl. $56^{\circ} \mathrm{N}$. ; and Serpieri gave R.A. $50^{\circ}-30^{\circ}$, Decl. $49^{\circ}-64^{\circ}$. Mr. J. E. Clark, in I874, undertook the projection of the tracks of about 2000 Perseids described in the "Luminous Meteor Reports" of the British Association, with the object of detecting motion in the radiant centre on successive days or hours of the night, but without definite success, though the observations suggested a progressive motion on succeeding nights similar to that noticed by Prof. Twining in 1859. In 1877 the shower was watched by the writer at Bristol on several nights, and the radiant was distinctly seen to take up a fresh position with every change of date. It moved from R.A. $40^{\circ}$, Decl. $56^{\circ}$, on August 5 to R.A. $60^{\circ}$, Decl. $59^{\circ}$ N., on August I6. The fact was first announced in NATURE for August 30, 1877 (vol. xvi. p. 362), and many observations in subsequent years at the same station have fully confirmed the shifting of the radiant, and indicated the long duration of the shower. In the following table will be seen the position of the radiant at intervals of five days :-

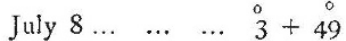

$$
\begin{aligned}
& \begin{array}{rlll}
13 \ldots & \ldots & \ldots & 3 \\
13 & 1 & 49
\end{array} \\
& \begin{array}{llll}
19 \ldots & \ldots & \ldots & 19+51
\end{array} \\
& 23 \ldots \ldots \ldots 25+52 \\
& \begin{array}{llll}
23 \ldots & \ldots & \ldots & 25 \\
28 & \ldots & \ldots & 3 \mathrm{I}+54
\end{array} \\
& \begin{array}{rrrr}
\text { August } & 2 \ldots & \cdots & 0 \\
& 6 & 0 \\
7 \ldots & \cdots & 42+57 \\
12 \ldots & \cdots & 50+57 \\
17 \cdots & \cdots & 60+58
\end{array}
\end{aligned}
$$

The whole duration extends, very probably, over the forty-five days from July 8 to August 22, and in the interval the radiant moves from $3^{\circ}+49^{\circ}$ to $77^{\circ}+57^{\circ}$.

This cluster is evidently one of enormous width, and has doubtless undergone distortion by the effect of planetary perturbation. Some interesting facts in connection with this and other cometary meteor systems will be found in the Sidereal Messenger for April and May I 886 . With regard to the August meteor-shower, it appears that a certain change in the position of the radiant ought theoretically to occur every night, but the observed displacement does not well accord with computation. On July 26 the Perseid radiant is about $4^{\circ}$, and on August 19 about $9^{\circ}$, from the radiant of its derivative comet (III. IS62); and these differences are doubtless to be referred to the disturbances exercised upon the original stream by the attraction of the earth. At every return of the group a vast number of the particles must obviously pass very near to us without being dissipated by the action of our atmosphere, and the paths of these will be affected to an extent that must alter the elements of their orbits.

Though the period of the August meteors has not yet been precisely ascertained, there is no question that the shower exhibits fluctuations from year to year as regards intensity, and that, like the two great systems of November, a certain cycle regulates its most brilliant displays. Future observations will determine the precise form of the orbit. The return of Comet III. 1862, or a recurrence of the very rich shower of August 1863 , will decide the matter, but as the orbit is one of considerable eccentricity, several generations may yet elapse before the period is accurately ascertained. It is certain that many of the supposed variations in the perennial intensity of the display are more apparent than real, because the successive returns are witnessed under different conditions. Cloudy or misty weather sometimes interrupts observation ; moonlight offers another impediment ; occasionally, also, the maximum is attained in daylight, and passes unheeded. The same observer is not always enabled to maintain an outlook from positions equally favourable; and there are other circumstances which, with those mentioned, prove the difficulty of securing a series of observations fairly comparable with each other. Usually about 40 or 50 meteors per hour may be counted by one observer before midnight on August 10 , but in the early morning hours of August II as many as 80 or 90 , perhaps more, will be seen, as the radiant is then higher and better placed for the visible distribution of its meteors.

"The August meteors," though a general term capable of being applied to any showers observed in the month of August, is commonly employed in special reference to the Perseids of August Io. There are large numbers of minor displays visible in the same month, the radiant points of which are scattered profusely over the firmament. There are certainly more than 100 showers in contemporaneous action with the Perseids, and many of these are now pretty well known, a mass of observations having accumulated for this particular epoch.

In the present year the great August shower has not been especially brilliant, though many of its meteors have appeared under their customary aspect. At Bristol, on August 2, 42 shooting-stars were counted during the $2 \frac{1}{2}$ hours between $1 \mathrm{oh}$. $50 \mathrm{~m}$. and $33 \mathrm{~h}$. $2 \mathrm{Im}$., and 14 of these were Perseids from a centre at $35^{\circ}+54^{\circ}$. On August 5, 3I meteors were seen in a similar interval, including I I Perseids. On August 8, in 3 hours from Ioh. to 13 h., 36 meteors were observed, and among these were 20 Perseids. The radiant, both on the and and 5 th, seemed to be at $42^{\circ}+57^{\circ}$. The few subsequent nights were overcast, but on the $13^{\text {th }}$ a clear sky permitted watching, and during the $3 \frac{1}{2}$ hours from $10 h$. to $13 \mathrm{~h}$. $30 \mathrm{~m}$. 49 meteors were seen, of which 13 were Perseids from a 
radiant at $52^{\circ}+57^{\circ}$. On August 14, between Ioh. and I 3 h., 25 meteors were noted, but there were only two Perseids amongst them.

On August S, Mr. Booth, at Leeds, watched the eastern sky for $4 \frac{1}{2}$ hours, and saw 45 meteors, including 25 Perseids. The radiant was at about $42^{\circ}+57^{\frac{1}{2}}$, and it will be observed that the proportion of Perseids to the total number of meteors observed was the same as noted at Bristol on that date. On August $\mathrm{I}_{3}, \mathrm{Mr}$. Booth recorded 13 Perseids from a radiant at $51^{1}{ }^{\circ}+56^{\circ}$, thus confirming the displacement observed at Bristol.

On August 10, Mr. G. T. Davis, of Theale, near Reading, reports the sky was clear and many meteors were visible between 9.30 and I I p.m., the majority being Perseids. The same observer recorded a number of paths on August 5 and 8 , and a comparison of his results with similar observations at Bristol show that 7 meteors were doubly observed at the two stations. Their heights, \&c., were computed by the writer as follows :-

\begin{tabular}{|c|c|c|c|c|c|c|c|c|}
\hline $\begin{array}{l}\text { Date. } \\
\text { I } 888 .\end{array}$ & $\begin{array}{l}\text { Hour: } \\
\text { G. M.T. }\end{array}$ & Mag. & 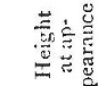 & 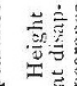 & . & 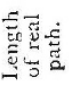 & 芯. & 焉 \\
\hline ug. & h. m. & & Miles. & Miles. & & Miles. & & \\
\hline & IO I9 & $\ldots \quad I-3$ & $\ldots 69$. & . 50 & & $37 \ldots$ & $50+55$ & ... 2 \\
\hline & IO 30 & ‥ $3^{-4}$ & .. 69 & .. 48 & $\cdots$ & $3^{8} \ldots$ & ‥ $39+57$ & $\ldots$ \\
\hline & IO 42 & ‥ $3-4$ & .. 68 . & $\cdots 4^{8}$ & $\ldots$ & $24 \ldots$ & .. $43+5$ & $\ldots$ \\
\hline & I0 6 & ․ $3-5$ & $\ldots 70$ & ... 59 & $\ldots$ & 28 & .. $66+56$ & $\ldots$ \\
\hline & IO IO & ... 3-4 & $\ldots 65$ & ‥ 52 & $\cdots$ & $3^{8}$ & $\cdots 319-13$ & ... \\
\hline & IO 2 I & ‥ 3-3 & ․ 43 & ... 28 & & 26 & ... $40+60$ & \\
\hline & I0 28 & .. $4-4$ & ... 68 & ... 48 & & & 57 & \\
\hline
\end{tabular}

The close agreement in the heights of these meteors fexcept in the case of No. 6 in the list, which was much nearer the earth's surface than usual) will be noticed. They were, with the exception of No. 6, which belonged to a radiant in Aquarius, all members of the August meteor system, though in several cases, notably that of No. 4, the path, as observed at Reading, was not exactly conformable to the radiant point of this shower.

The recent display has furnished us with a splendid fire-ball. It appeared on August 13 at 11 h. 33 m., and was seen by Mr. Booth at Leeds, by Mr. Monck at Dublin, by the writer at Bristol, and by several observers at Birmingham and other places. When near its disappearance the fire-ball acquired such brilliancy that it lit up the firmament like a vivid flash of lightring, and in the latter portion of its path there remained a comet-like streak which at Leeds and Birmingham continued visible for three minutes. The descriptions of this exceptionally fine meteor are in good agreement. It traversed a course above Yorkshire at normal heights; its brilliant streak had a mean elevation of 53 miles and length of 18 miles. No detonation appears to have been heard.

W. F. DENNiNG.

\section{NOTES.}

IT is proposed by the Organizing Committee of Section B that in the course of the approaching meeting of the British Association there shall be a discuscion in that Section upon the subject of "Valency." Prof. Armstrong will open the delate, and it is hopel that several other eminent chemists will take part. In the immediate neighbourhood of Bath there are no industries specially interesting to chemists, but arrangements are in progress by which it is hoped that members will be admitted to some of the works in and about Bristol, which is only ten miles away.

THE autumnal meeting of the Iron and Steel Institute was opened in the University, Edinburgh, on Tuesday. A hearty reception was given to the members in the Senate Hall by the Lord Provost (Sir Thomas Clark), Sir William Muir (Principal of the University), Prof, Armstrong (the honorary secretary of the Reception Committee), and other dignitaries and officials of the University. The members having adjourned to the Examination Hall of the University to begin the business of the meeting, the President, Mr. Daniel Adamson, announced that Sir James Kitson had been nominated by the Council as the President for the next two years, and he hoped that that would meet with the approval of the members. The Institute had intended, he said, to go to America for their next autumnal gathering, but the visit had been postponed until 1890 , as that was considered a more suitable time, especially as a kind invitation had been giren them to visit Paris next year, when the Exhibition was on. They would thus have an opportunity of entertaining their American friends. Sir Lowthian Bell took the chair while a paper on a levertesting machine, prepared by the President, was discussed. It described in detail a horizontal compound lever-testing machine. Mr. Wickslead (Leeds), Mr. G. C. Hemming (Yale and Towne Manufacturing Company, U.S.), Mr. Brown (of Brown Brothers, Ieith), M. Gautier (Paris), Mr. Nursey (London), and Sir Lowthian Bell took part in the discussion. A paper on manganese steel, by Mr. R. C. IIadfield (Sheffield), proved specially interesting, as it formed a guide to the exhibits of this metal at the Glasgow Exhibition.

THE third International Congress of Inland Navigation was opened at Frankfort-on-the-Main on Monday. It began with a speech from the President, Herr von Bötticher, Minister of State, who greeted those present in the name of the German Emperor. The Congress is divided into three sections. The first studies the improvement of river navigability, the best kind of boat for river navigation, and the best means of propulsion for boats. The second section occupies itself with the economic advantages of ship canals penetrating into the interior from river mouths, their navigability, and keeping in good order. The third deals with the reform of the statistics of interior navigation, and with the relations between agriculture and navigation.

ON Monday a paper by Dr. Gamaleia, of Odessa, on the cure of cholera by inoculation, was read to the Paris Academy of Sciences by M. Pasteur. The following informa. tion on the subject is given by the Paris Correspondent of the Times. It appears that in 1886 Dr. Gamaleia came to Paris as delegate of the Odessa doctors, and studied the Pasteur method, with which he made himself thoroughly acquainted. On his return to Russia various institutions were founded under his care for the cure of hydrophobia, which have proved very valuable. Five years ago M. Pasteur endeavoured to discover a means of curing cholera by inoculation. At his request a mission was sent by the French Government to Alexandria while cholera prevailed there, to study the subject. Dr. Lhuiller, one of the mission, died of cholera, and M. Pasteur did not press the continuance of the investigations. The subject, however, was taken up by Dr. Gamaleia, who has dis. covered a method similar to that of M. Pasteur, by which it is believed cholera can be cured by the inoculation of the cholera virus. As yet experiments have only been made on anima!s, but no doubt is entertained that it will be possible to apply in a short time the same process to man. After reading the paper, M. Pasteur stated that Dr. Gamaleia had expressed his readiness to repeat the experiments at Paris in presence of a committee of the Academy of Sciences, and to try on himself the inoffensive anil sufficient dose for human vaccination. $\mathrm{He}$ is ready to undertake a journey into countries where cholera prevails to prove the efficacy of his method. M. Pasteur added that he need scarcely say that he accepted with the greatest satisfaction the offer made by Dr. Gamaleia to conduct the experiments in his laboratory. The letter was referred to the committee, which has a prize of 100,000 francs in its hands for a cure for cholera, and it was arranged that the experiments should be postponed till November. 